\title{
PÓS-GRADUAÇÃO EM DIREITO NO BRASIL: 50 ANOS, INTEGRAÇÃO E DESAFIOS PARA O FUTURO
}

\author{
Francisco Luciano Lima Rodrigues ${ }^{1}$ \\ Martonio Mont'Alverne Barreto Lima
}

\begin{abstract}
Também o nome: Universidade, me lisonjeio, não precisará de nenhum pedido de desculpas de Sua Eterna Real Majestade. É apenas para indicar que nenhuma ciência é excluída, e que a instituição de ensino também concederá dignidade e graus acadêmicos. Qualquer outra coisa que seja obsoleta e obscura restará, é claro, à margem do caminho. Fundar uma instituição de ensino superior, mas não uma universidade, é lamentável, por mais sedutora que seja a ideia, devido a sua novidade e sua execução um pouco mais fácil. Nem mesmo o conceito de tal instituição pode ser firmemente definido; uma instituição meramente prática seria ainda mais perigosa, porque teoria e prática não devem ser separadas no ensino. ${ }^{3}$
\end{abstract}

Introdução

As palavras acima foram escritas por Wilhelm von Humboldt, em 12 de maio de 1809, quando de seu "requerimento" ao Imperador para a fundação de uma universidade em Berlim. A agora Universidade de Berlim foi fundada em 1809, e desde 1949 recebeu a denominação de Humboldt-Universität zu Berlin. O que se ressalta de tão breve discurso? Poder-se-ia elencar diversos pontos, especialmente em virtude da dimensão da obra de W. von Humboldt, cuja centralidade reside na linguística. O quê nos interessa ante a proposta do presente texto, é a concisão da ideia: a fundação de uma universidade, a abranger todas as áreas do conhecimento humano, numa perspectiva indissociável de teoria e práxis e de diálogo interno entre as ciências. Não surpreende

Professor Titular da Universidade de Fortaleza. Desembargador do Tribunal de Justiça do Ceará.

Professor Titular da Universidade de Fortaleza. Coordenador da Área de Direito na CAPES (2011-2014). Humbold, Wilhem von. Antrag auf Errichtung der Universität Berlin - Mai 1809. Wilhem von Humboldt. Werke, B. IV: Schriften zu Politik und zum Bildungswesen. Darmstad: WBG, 2010, p. 31. As traduções do presente texto são de responsabilidade dos Autores. No original: Auch der Name: Universität wird, schmeichele ich mir, bei Ew. Königlichen Majestät keiner Entschuldigung bedürfen. Er soll nur anzeigen, dass keine Wissenschaft ausgeschlossen seyn, und dass die Lehre-Anstalt auch akademischen Würden ertheilen wird. Alles sonst Veraltete und Nachtheilige fällt natürlich hinweg. Aber eine Lehreanstalt gründen, die höhere, und doch nicht Universität sey, ist, wie anlockend auch den Gedanken die Neuheit und die gewissermassen leichtere Ausführung macht, misslich, sich nicht einmal der Begriff eines solchen Instituts fest bestimmt lässt; eine bloß praktische Anstalt würde, weil Theorie und Praxis beym Unterricht nicht so geschieden seyn darf, noch gefählicher seyn. 
que a hoje Universidade Humboldt figure entre os mais destacados centros de excelência mundiais.

Se tais palavras tornaram-se ideias que mais tarde se materializam num modelo bem-sucedido de universidade, não há como escapar da reflexão mais próxima do Brasil, formulada mais de quarenta anos antes, iniciada precisamente em 29 de setembro de 1772, quando o Marquês de Pombal compareceu à Sala dos Capelos da Universidade de Coimbra para apresentar os "Estatutos da Universidade de Coimbra compilados debaixo da immediata e suprema inspecção de El Rey D. José I, nosso Senhor, pela Junta de Providência Literária creada pelo mesmo Senhor para a restauração da Sciencias e Artes Liberais nestes Reinos e todos seus Domínios". ${ }^{4}$

Quando se considera que na Faculdade de Medicina da Universidade de Coimbra estava proibida a dissecação de cadáveres, "por motivos religiosos", 5 é possível que se avalie a distância que se encontrava Portugal das luzes do século XVIII e da pressa do governo pombalino em superar o atraso científico. A fim de formar o diálogo científico para uma nova geração para a burocracia do Estado e pesquisadores científicos, os estudantes de Direito - Leis e Cânones - foram obrigados, por exemplo, a cursar a "cadeira de matemática, considerada subsidiária do Direito". 6

As duas experiências exitosas rapidamente aqui mencionadas, além de reforçarem a óbvia compreensão de que não há como fugir da racionalidade da profunda historicidade dos acontecimentos, despertam nossa atenção para o caso brasileiro, especialmente quando se pretende percorrer a trajetória da pós-graduação em Direito no Brasil nos seus cinquenta anos.

Há diversas lentes a tornarem possível a investigação sobre esse tema. Desde os primórdios dessa pós-graduação e as razões de todas as ordens que levaram a intelectualidade jurídica nacional à decisão de fundar a chamada formação de excelência até os esforços financeiros para a pós-graduação em geral no País são aspectos que caberiam nesta reflexão. Porém, a fim de que se limite este rápido estudo, trataremos aqui da situação atual da pós-graduação em Direito no Brasil - a qual resulta de seu acúmulo histórico, por mais distante que esteja e pareça -, no seu quadro atual de integração nacional e estrangeira. Em outras palavras, procuraremos enfrentar: a) o que pode oferecer a pós-graduação em Direito ao País, notadamente à intelectualidade jurídica nacional; b)

4 Boto, Carlota. O Iluminismo e as Reformas Pombalinas, p. 16. In: As Reformas Pombalinas no Brasil. Org. Thaïs Nivia de Lima e Fonseca. Belo Horizonte: Mazza Edições, 2011, p. 9-48.

5 Maxwell, Kenneth. Marquês de Pombal - Paradoxo do Iluminismo. Rio de Janeiro: Editora Paz e Terra, 1996, p. 110.

6 Villalta, Luiz Carlos. A Universidade de Coimbra sob o reformismo ilustrado português (1770-1807), p. 172. In: As Reformas Pombalinas no Brasil. Org. Thaïs Nivia de Lima e Fonseca. Belo Horizonte: Mazza Edições, 2011, p. 157-202. 
a localização da pós-graduação em Direito brasileira diante da desordenada expansão da graduação; e c) o desafio brasileiro de manter a qualidade de sua pós-graduação em Direito ante a também expansão de modelos de pós-graduação distantes do que se exige pela comunidade científica do Direito.

É fato que este debate ainda não está concluído no Brasil, como também é verdade que não há obstáculo para sua efetivação, apesar das deficiências presentes nos últimos cinquenta anos.

O que pode oferecer a pós-graduação em Direito no Brasil?

Não há deixar de reconhecer as deficiências do sistema brasileiro de pós-graduação em Direito. Até a metade dos anos 90, somente uma instituição, a Universidade Federal de Pernambuco, oferecia curso de pós-graduação em Direito nos níveis de mestrado e doutorado nas regiões Norte e Nordeste. Para a demanda atual da população dessas regiões não se pode dizer que há muitos cursos: no Nordeste, somente quatro, e uma instituição de ensino superior da região Norte oferecem cursos nos níveis de mestrado e doutorado. O panorama era mais desanimador se se considerava a região Centro-Oeste: apesar de contar com curso de mestrado desde 1975, somente em 2005 a Universidade de Brasília implantou seu curso no nível de doutorado.

Por outro lado, parece não restar dúvida de que a proliferação de cursos no nível de mestrado e de mestrado profissional resulta numa expansão a alcançar todos os Estados do Nordeste, especialmente com a implantação do primeiro programa de pósgraduação no interior do Nordeste, em Mossoró, abrigado pela Universidade Federal Rural do Semi Árido. ${ }^{7}$ Hoje todos os Estados das regiões Nordeste, Sudeste e Sul possuem mestrados e doutorados em Direito. No Centro-Oeste somente um Estado não conta com pós-graduação em Direito; no Norte quatro Estados não contam com essa pós-graduação.

Quando se leva em conta os números das regiões Sudeste e Sul, constata-se a consolidação da expansão da rede da pós-graduação em Direito, igualmente a ocorrer no interior dessas regiões, isto é, programas fora dessas capitais estaduais.

Pode-se afirmar que todas as áreas do Direito são cobertas pelos programas de pós-graduação; afirmação que não era possível há trinta anos. Para além das áreas mais tradicionais - Direito público e privado - hoje é possível realizar pesquisa em Direito digital, por exemplo. Há programas que se dedicam em suas áreas de concentração ou

\footnotetext{
7 Esta e todas as informações sobre os números da pós-graduação em Direito no Brasil são provenientes da CAPES, disponíveis em: https://sucupira.capes.gov.br/sucupira/public/consultas/coleta/ programa/ quantitativos/quantitativoIes.jsf?areaAvaliacao=26\&areaConhecimento=60100001. Acesso em: 10 nov. 2020 .
} 
linhas de pesquisa estruturantes ao Direito Amazônico; ao novo constitucionalismo latino-americano; à teoria da argumentação jurídica; aos direitos fundamentais e sociais. As novas formas do Direito Civil fizeram com que surgissem pesquisadores (com publicações, grupos de pesquisa com vínculos nacionais e internacionais) que verticalizam suas investigações: não se trata mais de estudar o Direito de Família, mas as novas modalidades de unidades familiares. Não se busca mais pesquisar o Direito das Coisas, mas o sentido da propriedade e as mudanças que o conceito enfrenta desde o final da Segunda Guerra Mundial. Parece ser claro que esses fatos são sintomas da existência de não somente de um maior número de profissionais de docência e pesquisa em Direito, mas também de uma disposição em seguir tendências mundiais de pesquisa sobre âmbitos do Direito que se apresentavam até então na forma de blocos.

Um considerável número de docentes obteve sua formação de excelência, dos anos noventa até os dias atuais, no exterior: seja de forma mais duradoura, isto é, com quatro a cinco anos de permanência no exterior; seja na forma de permanência mais curta, de um a dois anos. Referido intercâmbio trouxe consequências positivas ao sistema brasileiro de pós-graduação em Direito. Não somente porque os pesquisadores brasileiros foram receptores do pensamento e dos debates estrangeiros, mas igualmente pela razão de que pesquisadores brasileiros em Direito que começaram sua atuação nos anos noventa passaram a integrar grupos e publicações de pesquisas internacionais. Esta percepção deixou-se registrar também no Relatório de Avaliação do ano de 2013, que avaliou a pós-graduação em Direito relativa aos anos de 2010, 2011 e 2012: "a Área de Direito caracteriza-se pelo forte envolvimento de seus corpos docente e discente em agendas políticas e sociais, seja na perspectiva local, regional e nacional, e, para parte significativa da Área, internacional". ${ }^{8}$

Esta abertura, com certeza, conduziu o rumo da pós-graduação para diálogos para fora do Direito, o que significa não o abandono do que se convencionou chamar a dogmática jurídica, porém, passou-se a incorporar ciências como a História, Teoria Política, Sociologia como chaves à análise e compreensão do Direito. A Filosofia, por óbvio, já integrava o rol dos chamados diálogos com o Direito, como grande autonomia pedagógica, pelo menos, desde o século XVIII. É evidente que o Direito passava pelo crivo da Filosofia desde tempos imemoriais, porém com forte submissão às ponderações teológicas, cujo melhor exemplo foi o jusnaturalismo e sua força teórica ainda nos dias atuais. ${ }^{9}$ A ruptura operada por Baruch de Spinoza com o seu Tratado

8 CAPES. Relatório de Avaliação 2010-2012. Disponível em: https://www.gov.br/capes/pt-br/centrais-deconteudo/Direito1.pdf. Acesso em: 15 jun. 2018.

9 Espinosa, Baruch de. Tratado Teológico-Político. São Paulo: Martins Fontes, 2003, p. 223/224. Um significativo esforço intelectual do jusnaturalismo no Brasil veio com a obra de Arnaldo Vasconcelos: Teoria da Norma Jurídica (Rio de Janeiro: Forense, 1986); Direito, Humanismo e Democracia (São Paulo: 
Teológico Político começou a questionar a suposta racionalidade da teologia e o papel da Filosofia como única possibilitadora da elaboração do pensamento racional: "Quem, pelo contrário, faz da razão e da filosofia servas da teologia, terá de admitir como coisas divinas preconceitos populares de tempos antigos, deixando que estes o ceguem e the inundem a mente. Um com a razão, outro sem ela, vão ambos, por certeza, ensandecer". ${ }^{10}$

O reconhecimento deste diálogo da pós-graduação em Direito com outras ciências vê-se pela palavra de observadores: ${ }^{11}$

Percebe-se também que a interdisciplinaridade é uma das marcas das pesquisas. Não obstante, nos estudos mais recentes, há diálogos constantes e consistentes com todas as ciências em geral, mas especialmente com a filosofia, a história, a sociologia, a economia e a antropologia. Também é perceptível a tendência, na linha do que já se faz em diversos países de forte tradição universitária, de publicação de pesquisas através de obras monográficas e em obras coletivas.

Se o panorama até aqui descrito é mais positivo, não quer dizer que sejam inexistentes deficiências e problemas na pós-graduação Direito brasileira. Seria necessária uma análise subjetiva, de longo fôlego, que poderia identificar precisamente uma das principais deficiências que nem mesmo acompanhamento e avaliações permanentes pela CAPES conseguiram oferecer solução: a qualidade da produção intelectual dos programas dispersa e centrada na quantidade.

De modo a incrementar a reflexão a respeito do assunto, vale compartilhar a percepção construída pela experiência de mais de 15 anos como docentes de programa de pós-graduação em Direito, onde, por interagir com outros programas e integrar comissões trienais de avaliações da área de Direito perante a CAPES, foi possível verificar que a priorização da quantidade para fins de classificação dos programas de pós-graduação prossegue como um calcanhar de Aquiles. Se por um lado, fortalecer a quantidade da produção intelectual, fazendo com que grandes nomes de programas já consagrados nacionalmente produzam, estimula e obriga à produção dos demais, por outro, a centralidade do publish or parish pode levar às "imposturas intelectuais": "La

Malheiros, 1998); Direito e Força - Uma visão pluridimensional da coação jurídica (São Paulo: Dialética, 2001); e A Teoria Pura do Direito de Hans Kelsen - Repasse crítico de seus principais fundamentos (São Paulo: Malheiros, 2003).

10 Tanto a informação falsa sobre o local da publicação e do editor, constante na própria obra, como a proibição de sua circulação já em 1674 oferecem dimensão do significado desta obra para a filosofia ocidental.

11 Gameiro, Ian Pimentel Gameiro e Gilberto Guimarães Filho. O mapa da pós-graduação em Direito no Brasil: uma análise a partir do método da Social Network Analysis. Revista Direito GV. São Paulo, v. 13, n. 3, set-dez 2017, p. 891-920, p. 893. DOI: http://dx.doi.org/10.1590/2317-6172201735. 
única solución, pienso es prestar menos atención a las credenciales y más atención 'una atención crítica - al contenido de lo que se dice". ${ }^{12}$

A desatenção que se presta "ao conteúdo do que se diz" quando dos processos de avaliação tem se constituído em sério problema já detectado pela mesma CAPES, quando os cursos de pós-graduação brasileiros foram surpreendidos com as notícias, durante a avaliação realizada em 2013, com arranjos clandestinos para impulsionar fator de impacto da produção intelectual de periódicos e artigos. ${ }^{13}$

Talvez o produtivismo que se tem exigido até aqui consista mesmo no mais significativo desafio à consolidação da produção científica da pós-graduação brasileira em Direito. Por outro lado, emerge o obstáculo que impede formule um controle sobre essa produção. O Direito, como qualquer das ciências, possui teorias distintas, posicionamentos diferenciados e amplos campos de investigação. Como qualificar produção intelectual dos pares? Qual a autoridade que professores experimentados ou não possuem sobre seus colegas, igualmente experimentados ou não?

Não se discute os extremos, certamente: há trabalhos de baixa qualidade que podem ser facilmente assimilados como tal, sem que essa crítica esconda eventual divergência teórica ou posições pessoais: aqui se trata da produção notoriamente absurda e estéril, o que pode ser detectado sem maior esforço. Mas ainda que assim seja, este não é o quanto da enorme maioria da produção, que resulta de esforços e pesquisas, e que será alisada por quem pensa noutro referencial teórico.

Em todo caso, tem-se que a pós-graduação brasileira em Direito pode oferecer uma formação bastante razoável, e que seu percurso nestes cinquenta anos apresenta saldo mais positivo que negativo. A organização do acúmulo histórico dos dados da pós-graduação nacional confirma a disposição do Estado brasileiro para elaborar política científica. Tal comportamento se mostra maior em determinados governos que noutros, revela o percurso dos cinquenta anos a tornar quase única nas Américas a organização de um sistema de acompanhamento e avaliação como o da CAPES.

Definida assim em rápidas palavras, a pós-graduação enfrenta ainda outro desafio: a integração regional, que trataremos a seguir.

12 Sokal, Alan. Más allá de las imposturas intelectuales - ciência, filosofía y cultura. Barcelona: Paidós, 2008, p. 15. Cf. ainda: Francis Wheen. Como a picaretagem conquistou o mundo. Rio de Janeiro: Editora Record, 2007.

13 Disponível em: https://oglobo.globo.com/sociedade/ciencia/empresa-aponta-possivel-fraude-emperiodicos-cientificos-brasileiros-9722072. Acesso em: 10 nov. 2020. http://opiniaoenoticia.com.br/ brasil/periodicos-cientificos-brasileiros-sao-acusados-de-fraude/. Acesso em: 10 nov. 2020. 
A localização da pós-graduação brasileira em Direito diante da desordenada expansão da graduação

De acordo com o Censo da Educação Superior de 2019, o número de vagas presenciais oferecidas em cursos de graduação subiu de $5.038 .392 \mathrm{em} 2014$ para 6.029.702 em 2019, traduzindo um incremento de 5,4\%. ${ }^{14} \mathrm{O}$ que surpreende é o aumento do número de vagas surgidas para ensino à distância, no mesmo período entre 2014 e 2019, num percentual de 45\%: de 3.042977 para 10.395 .600 vagas ofertadas.

A participação do número de matrículas na rede privada de ensino superior no Brasil é da ordem de 75,8\%, restando claro que a rede privada atende mais de dois terços de todos os alunos em cursos superiores. ${ }^{15}$ Direito é o curso com o maior número de matrículas: foram 815.959 alunos matriculados no ano de 2019, comparados com 652.476 em 2009. ${ }^{16}$ Em 2009, o curso de Direito ficava atrás apenas do curso de Administração quanto ao número de alunos matriculados. Em 2019, Direito supera todos os outros e é o curso com o maior número de matrículas. São 1.670 cursos de Direito em 2019.

Poucos autores criticaram a baixa qualidade do ensino da graduação em Direito como Lenio Luiz Streck. Inúmeras de suas colunas semanais num dos sítios da rede mundial mais lidos por juristas, o CONJUR, enfrentam o tema. O resultado do elevado número de cursos de Direito, bem como da superficialidade como essa ciência é estudada tem conduzido a equívocos que resultam no comprometimento da democracia brasileira; crítica com a qual não há como discordar. Um dos aspectos mais lembrados por Streck é o pan-principialismo ou pamprincipialismo, ou ainda na sua versão encontrada na "wikipédia": panprincipiologismo. ${ }^{17}$ Desde 2011, Lenio Streck adverte sobre a vulgarização dos princípios no estudo do Direito, que se define por conceitos estruturados de forma voluntarista por juristas, sem qualquer compromisso com a deontologia jurídica da reflexão da razão - e menos ainda com o rigor científico. Há princípios para todos os gostos e ocasiões, como o da "não surpresa", da "afetividade", da "alteridade", da "benignidade", da "cortesia" etc. ${ }^{18}$

O caso dos princípios é apenas um dos sintomas dos efeitos de que resulta a expansão da graduação sem controle de qualidade. Como se não bastasse ausência de acervo bibliotecário físico e virtual, remuneração digna dos docentes, incentivos à

14 Censo da Educação Superior de 2019, p. 12. Disponível em: http://download.inep.gov.br/educacao _superior/censo_superior/documentos/2020/Apresentacao_Censo_da_Educacao_Superior_2019.pdf. Acesso em: 12 nov. 2020.

15 Id. Ib., p. 26.

16 Id. Ib., p. 50.

17 Disponível em: https://pt.wikipedia.org/wiki/Panprincipiologismo. Acesso em: 16 nov. 2020.

18 Streck, Lenio Luiz. Verdade e Consenso - Constituição, Hermenêutica e Teorias Discursivas. São Paulo: Saraiva, 2012, p. 518 et seq. 
formação docente e discente por meio da formação de grupos de pesquisa e produção científica, a expansão da graduação que se vivencia reflete na pós-graduação em Direito. Se é certo que a pós-graduação não serve para corrigir as deficiências da graduação em Direito, não há como fugir da realidade de que discentes que integram os programas de pósgraduação em Direito são os egressos dessa graduação. Portanto, o impacto é inevitável. Mesmo que se tenha desenvolvido técnicas nos processos seletivos para ingresso na pósgraduação e que exigem mais dos candidatos - como domínio de um idioma estrangeiro, capacidade de elaboração de projeto de pesquisa, entrevistas presenciais com candidatos - as deficiências não se deixam amenizar por tais técnicas, e a pós-graduação em Direito acaba por incorporar discentes de baixo rendimento acadêmico e científico.

As informações da Plataforma Sucupira da CAPES dão conta da evolução da pós-graduação brasileira em Direito mais recente: ao final da avaliação trienal de 2013 eram 84 cursos $;{ }^{19}$ ao cabo da avaliação agora quadrienal de 2017 eram 99 cursos. ${ }^{20}$ Como ainda não se concluiu a avaliação quadrienal relativa aos anos de 2017 a 2020, a informação da página da área de Direito na CAPES é de atualmente $132 \operatorname{cursos}^{21}$ de pósgraduação em Direito no Brasil em 2019.

Observa-se que o crescimento da pós-graduação em Direito possui um ritmo bastante inferior àquele da graduação. Possivelmente o sistema de avaliação e acompanhamento da pós-graduação brasileira, com inúmeras exigências para a recomendação de um programa de pós-graduação, seja um dos motivos para este menor crescimento.

Desde exigências de instalações físicas até a análise do compromisso da instituição de ensino superior requerente com a implantação e o sucesso da proposta apresentada, são muitos os detalhes a serem examinados. Ainda que se tenha critérios subjetivos, dados objetivos permitem que se torne possível a aferição da satisfação dos critérios definidos pela respectiva Área. Não se deve olvidar que tais critérios derivam de decisão das próprias Áreas. Em outras palavras: a comunidade científica atuante em programas de pós-graduação é quem define os critérios constantes da ficha de avaliação para que uma proposta de curso novo seja aprovada. Assim, tem-se que os resultados da recomendação e da avaliação contínua dos programas recaem sobre os docentes pesquisadores daquela Área. A participação da CAPES consiste em organizar - ou

19 CAPES. Relatório de Avaliação 2010-2012. Disponível em: https://www.gov.br/capes/pt-br/centrais-deconteudo/Direito1.pdf. p. 28. Acesso em: 15 out. 2020.

20 CAPES. Relatório de Avaliação 2013-2016. Disponível em: http://avaliacaoquadrienal.capes.gov.br/ resultado-da-avaliacao-quadrienal-2017-2. p. 2. Acesso em: 15 out. 2020.

21 Disponível em: https://sucupira.capes.gov.br/sucupira/public/consultas/coletaprograma/quantitativos/ quantitativoAreaConhecimento.jsf?areaAvaliacao=26. Acesso em: 10 nov. 2020. 
coordenar - as Áreas as quais se agrupam em colégios e decidem critérios mais gerais. As especificidades são definidas por cada uma das Áreas de avaliação.

Como as outras Áreas, aquela de Direito definiu seus critérios no documento da Área e que explica os requisitos de ingresso no sistema de recomendação da CAPES até a avaliação do curso, no sentido de receber nota superior ou inferior. A definição desses critérios é que responde pelas exigências e procura manter com qualidade o crescimento da Área de Direito. De forma bastante distinta daquela da graduação, como se viu a partir do dado objetivo numérico, o avanço da pós-graduação em Direito procurou parâmetros que correspondessem à aplicação dos níveis internacionais. Naturalmente que a adoção deste modelo foi objeto de incompreensões e favorece a ocorrência de forte debate no interior da Área de Direito até hoje.

Como exigência geral da pós-graduação brasileira, desde o final dos anos 1990, passou-se a avaliar docentes, discentes e a instituição de ensino superior mantenedora do programa. Esta decisão consistiu na grande alteração do sistema de avaliação e acompanhamento dos programas de pós-graduação em Direito no Brasil. Desse processo restou conhecido o fato de que, a partir do novo modelo de avaliação e acompanhamento, a comunidade do programa seria responsável pela melhora, piora ou descredenciamento do programa ao qual participa. Não se tratava mais de considerar somente o número de egressos, prazos para titulação ou outro dado objetivo. Agora, entrava em cena o caráter decisivo da produção científica docente e discente, devidamente realizada, publicada em periódicos ou livros também avaliados pela mesma comunidade acadêmica. O envolvimento dos corpos docente e discente na pesquisa, na obtenção de financiamento para pesquisa, sob a forma de redes nacionais e internacionais, tornou-se critério à Área de Direito, quando eram já conhecidos da chamada ciência da natureza. Até a presente data, a Área de Direito não possui programa que tenha recebido a mais elevada nota da avaliação quadrienal da CAPES, que é a nota 7.

No interior da Área de Direito o debate a respeito da aplicação da nota máxima a um programa de pós-graduação em Direito tem ocorrido, havendo quem defenda que um ou dois de seus programas seriam dignos de tal nota. No entanto, tal entendimento tem encontrado resistência no âmbito dos órgãos colegiados internos da CAPES, e de cuja concordância é necessária para a obtenção dessa nota.

Parece quase natural, então, que com tantos novos pontos para o início do funcionamento de um programa de pós-graduação a expansão dessa rede de pósgraduação em Direito tenha sido mais cuidadosa. Uma rápida olhada para os critérios da ficha de avaliação da área de Direito dissipa dúvidas sobre as exigências para pedido de 
cursos novos e sua posterior avaliação. ${ }^{22}$ São três quesitos que se subdividem em itens: programa, formação e impacto na sociedade. Exige-se que o programa tenha docentes com o perfil e compatibilidade e adequação à proposta do programa; que seja analisada a qualidade da produção intelectual de discentes e egressos, o destino, atuação e avaliação dos egressos do programa em relação à formação recebida, bem como a qualidade das atividades de pesquisa e da produção intelectual do corpo docente no programa. Por fim, exige-se que se comprove o impacto e caráter inovador da produção intelectual em função da natureza do programa, o impacto econômico, social e cultural do programa, e ainda sua Internacionalização, inserção (local, regional, nacional) e visibilidade do programa. Tais pontos eram impensáveis até o final dos anos noventa!

Que frutos foram colhidos até hoje? Pode-se dizer com segurança que foram muitos e, na sua grande maioria, bons frutos. É possível se afirmar que uma instituição de ensino superior que decida pela implantação de um programa de pós-graduação sinalize maturidade. Os esforços acadêmico, científico e financeiro não são poucos para que uma instituição de ensino superior consiga a aprovação de uma proposta de curso novo.

Essa instituição sabe que o retorno trazido pela existência e ascensão de um de seus programas de pós-graduação se revela na qualidade de sua inserção e de sua reputação. Portanto, está-se diante de uma escolha pela qualidade, sem a certeza de retorno financeiro.

Quando se analisa este quadro em relação às instituições privadas, se mostra possível compreender positivamente a cultura acadêmica dessa instituição, a partir de sua opção por privilegiar a criação de programa de pós-graduação.

Há um aspecto que deve ser notado. Após o crescimento da pós-graduação em Direito, percebeu-se difusa formação de centros de referência, além da dificuldade de diálogo entre programas nacionais, como diagnostica Marcelo Varella: ${ }^{23}$

A pós-graduação brasileira é regional. Ela se universaliza
com base em docentes disponíveis localmente, formados
no curso de doutorado mais próximo. Não há nenhuma
universidade que consiga ter forte influência nacional.
Mesmo as grandes universidades têm apenas um ou dois
professores titulados em diferentes programas. Além disso,
nota-se que mesmo localmente, há pouca comunicação de
talentos entre as universidades tradicionais, sobretudo na
USP, na PUC-SP e na UFMG. A tradição é absorver seus
próprios titulados e não criar mecanismos de diálogo na
composição do corpo docente. Infelizmente, esse cenário

22 https://www.gov.br/capes/pt-br/centrais-de-conteudo/direito-ficha-avaliacao-pdf. Acesso em: 10 nov. 2020.

23 Varella, Marcelo. Quem influencia a Pós-Graduação em Direito no Brasil? Uma Análise Empírica da Nucleação Acadêmica. Revista de Direito Brasileira, a. 5, v. 12, p. 111-127, 2015. p. 126. 
dificulta a produção coletiva do conhecimento e a troca de experiências entre as universidades. A formação de redes de pesquisa interinstitucionais como método de produção coletiva do saber precisa ser estimulada. Isso parte, de um lado, na circulação do conhecimento e, de outro, na vontade de conhecer, dar oportunidades e absorver o conhecimento produzido pelos colegas do mesmo país.

Se o problema da ausência de diálogo e a construção de redes de pesquisa nacionais estava visível em 2015, parece que as novas diretrizes tendem a melhorar o quadro. Não que se realizem esforços no sentido de criar órbitas de gravitação de poucos programas. A difusão da influência de dada instituição e seu programa parece ser mais positiva do que negativa, na medida em que não deixa de ser um retrato das distinções, em todos os sentidos, de um país com as dimensões do Brasil. O verdadeiro problema é a ausência do diálogo científico entre os programas. Pelo menos, como se viu acima na nova formulação da ficha de avaliação da Área de Direito, tal aspecto foi assimilado e se converteu em elemento a ser exigido dos programas de pós-graduação em Direito.

O crescimento relativo aos egressos dos cursos de graduação em Direito, como não poderia deixar de ser, exerceu pressão sobre a pós-graduação. Se procede a crítica a respeito da necessidade nacional da formação de excelência nas regiões mais carentes do País, por outro lado, ao se flexibilizar parâmetros científicos, corre-se o risco de que padece a graduação: expansão da graduação com nível de pamprincipialismo!

No Brasil, desde a primeira década do século XXI, observou-se curioso fenômeno como resposta ao que seria o lento crescimento da oferta por cursos de pós-graduação em Direito: a oferta de cursos nos níveis de mestrado e doutorado nos países do Mercosul e da Europa, como justificativa da insuficiência das vagas que a pós-graduação brasileira em Direito seria capaz de pôr à disposição de um grande número de graduados em Direito. A integração internacional da ciência do Direito brasileira, no nível de excelência, que se transformou em parâmetro de aferição da boa qualidade de um programa se transformou em vilã, a fim de justificar a necessidade de pronto reconhecimento de títulos obtidos em cursos de pós-graduação fora do Brasil. Talvez hoje esse ainda se constitua num dos principais desafios da pós-graduação brasileira.

O desafio brasileiro de manter a qualidade de sua pós-graduação em Direito

Se um dos aspectos centrais das mudanças ocorrida na política científica da pós-graduação nacional se operou a partir do final dos anos noventa, deve ser registrado que o quesito mais relevante passou a ser a produção intelectual. A Área de Direito também seguiu este rumo. Passou a exigir de seus pesquisadores com atividade em programa de pós-graduação não somente que sua produção estabelecesse vínculos com 
grupos de pesquisa interno e externos ao programa respectivo, como ainda requereu, para fins de classificação da nota superior a 5 (sempre na escala das notas de classificação dos programas de pós-graduação, a qual vai de 1 a 7), que essa produção fosse publicada em periódicos conceituados, sejam eles nacionais ou internacionais. O nível de exposição da produção científica dos programas de pós-graduação em Direito teve que contar ainda com parâmetro das publicações internacionais, e com parcerias de pesquisa igualmente internacionais.

É que se entendeu que um dos caminhos para que a pós-graduação brasileira em Direito se afirmasse internacionalmente seria o enfrentamento da ocorrência da recepção internacional da produção intelectual nacional. Para além de alcançar ambiciosa meta, estava em jogo outra questão, agora de ordem mais complexa: a de que as formulações intelectuais brasileiras conseguissem compreender e traduzir as peculiaridades do Direito para seu próprio País.

Não se discute que a recepção da cultura e do pensamento produzido no centro europeu seja importante e possua credenciados pressupostos de reflexão que devem ser assimilados no Brasil. O detalhe aqui é outro: há a necessidade de se compreender, por exemplo, o que significa federalismo, direito de propriedade, jurisdição constitucional, separação de poderes, república para a realidade brasileira. Como em qualquer outro país, a profunda historicidade que conceitos e instituições jurídicas possuem no Brasil indicam que a recepção das teorias europeias e emanadas da América do Norte é importante, mas está distante de oferecer resposta para os desafios brasileiros. A investigação de tais respostas pode perfeitamente ser conduzida pela intelectualidade nacional, que praticará formulações com os olhos voltados para o ambiente interno. Não custa lembrar que as advertências das experiências estrangeiras, lidas pelos pesquisadores brasileiros, exerce o mesmo papel que as advertências da experiência brasileira perante pesquisadores de outras nacionalidades. A reciprocidade e troca de conhecimento fortalece redes científicas e é capaz de oferecer explicações para a natureza dos fenômenos jurídicos.

Quando se observa as avaliações trienal de 2013 e quadrienal de 2017, chama a atenção a evolução da produção intelectual em periódicos de classificação nos estratos mais elevados. Apenas para finalidade deste texto escolheu-se os periódicos em razão de sua centralidade para a classificação da produção intelectual.

A classificação dos periódicos obedece àquilo que a Área de Direito produz. São classificados os periódicos onde a produção dessa área é veiculada. Podese afirmar, assim, que a classificação corresponde ao comportamento de publicações da Área. Não há idealidade de classificação: este ou aquele periódico não pode ser classificado, ainda que se constitua em referência internacional. Se nenhum pesquisador brasileiro nele publicou, há duas consequências possíveis: ou os pesquisadores não dirigiram sua produção a esse periódico; ou se dirigiram a tais periódicos, não logrando 
aprovação da publicação. Em todo caso, se um periódico, ainda que renomado, não traz publicação brasileira não será classificado. Evidente que tal ausência sinaliza alerta, uma vez que não parece razoável que a produção científica nacional ignore tais periódicos ou revistas, independentemente de sua nacionalidade de origem.

No ano da avaliação de 2013, eram apenas 51 periódicos nacionais e internacionais classificados no estrato A1, o mais elevado. Esse número de periódicos correspondia apenas a $2,24 \%$ da listagem total dos periódicos. No segundo estrato mais elevado da classificação, o A2, estavam elencados 75 periódicos correspondentes a 3,29\% do total. Como se vê, até 2016 os pesquisadores brasileiros dirigiam suas publicações a pouco mais que $5,5 \%$ dos periódicos e revistas melhores classificados pelos mesmos pesquisadores, na forma da tabela abaixo: ${ }^{24}$

\begin{tabular}{|l|r|r|}
\hline Estrato & Quantidade & \multicolumn{1}{|c|}{ Percentual } \\
\hline A1 & 51 & 2,24 \\
\hline A2 & 75 & 3,29 \\
\hline B1 & 180 & 7,90 \\
\hline B2 & 93 & 4,08 \\
\hline B3 & 139 & 6,10 \\
\hline B4 & 126 & 5,53 \\
\hline B5 & 222 & 9,74 \\
\hline C & 1393 & 61,12 \\
\hline Total & 2279 & 100 \\
\hline
\end{tabular}

No ano da avaliação quadrienal de $2017,{ }^{25}$

(...) foram avaliados 2.059 periódicos, o que significou um crescimento de $24,48 \%$ em relação a 2016 , quando foram avaliados apenas 1.654 periódicos (...) Dos 2059 periódicos avaliados em 2017, 67 foram classificados no estrato A1, 80 no A2, 221 no B1, 180 no B2, 147 no B3, 164 no B4 e 257 no B5, totalizando 1116 periódicos.

Significativa novidade na última avaliação quadrienal realizada em 2017 foi a inclusão do fator de impacto da área na classificação dos periódicos, conforme indicado no documento a relatar essa avaliação: "Índice de impacto do JCR, SJR ou Google Acadêmico ou indexação no Web of Science, Scopus para o estrato A1,

24 Disponível em: CAPES. Relatório de Avaliação 2010-2012. Disponível em: https://www.gov.br/capes/ pt-br/centrais-de-conteudo/Direito1.pdf. p. 5. Acesso em: 15 out. 2020.

25 CAPES. Relatório de Avaliação 2013-2016. Disponível em: http://avaliacaoquadrienal.capes.gov.br/ resultado-da-avaliacao-quadrienal-2017-2, p. 11. Acesso em: 15 out. 2020. 
valorizando-se, ainda, a indexação no SciELO para o estrato A2, e sempre que respeitado o limite fixado pelo CTC de ter menos periódicos no estrato A2 do que no A1". ${ }^{26}$

$\mathrm{O}$ que se pode concluir de tal direcionamento da produção intelectual? Cremos que parece ser possível afirmar que a pós-graduação brasileira em Direito procura sua interação nacional e inserção internacional, demonstrando um necessário esforço nesse sentido. Não parece restar muita dúvida de que a busca pela preservação dessa qualidade exige um caminho mais cuidadoso, logo mais lento, incompatível com o crescimento dos cursos de graduação, o que explica a fixação de exigências de nível internacional.

Referido conjunto de decisão da pós-graduação em Direito levou a alternativas pouco recomendáveis. A principal delas de materializou na oferta de curso de doutorados "express", como à época mencionou matéria jornalística em meio de circulação nacional. Diante deste fato, pode-se constatar a importância do assunto pela dimensão que lhe foi atribuído por um grande veículo de imprensa nacional que fez do assunto pauta de suas publicações. ${ }^{27}$

Cursos no nível de mestrado e doutorado passaram a ser oferecidos, com permanência concentrada geralmente quinzenal, onde discentes brasileiros se deslocavam aos locais oferecidos para tal curso.

A principal crítica que se aplicava ao sistema nacional da pós-graduação em Direito para o oferecimento desses cursos em países europeus e do Mercosul era a "reserva de mercado" praticada pela CAPES e sua Área de direito; argumento improcedente, mesmo quando se compara o tempo em que tais cursos mais proliferaram e onde o enfrentamento com a área de Direito e a CAPES foi mais visível: ${ }^{28}$

O ritmo da abertura de cursos avançou significativamente nos últimos anos. Até 1980, havia no País apenas 11 programas de mestrado e 3 de doutorado. Eram cursos mais antigos, tradicionais, como na Universidade Federal de Minas Gerais (UFMG), na Universidade de São Paulo (USP) ou Pontifícia Universidade Católica de São Paulo (PUC-SP). Na década de 1980, quase não houve abertura de novos cursos, sendo o único curso de doutorado criado na Universidade Federal de Santa Catarina. A partir de 1990, nota-se uma ampliação rápida do sistema, seguindo a política de indução do Governo Federal. Entre 1990 e

26 Id. Ib, p. 14.

27 Disponível em: https://www1.folha.uol.com.br/paywall/login.shtml?https://www1.folha.uol.com.br/ cotidiano/2013/03/1239876-advogados-vao-a-argentina-fazer-doutorado-express.shtml. Acesso em: 10 nov. 2020.

28 Varella, Marcelo Dias e Martonio Mont'Alverne Barreto Lima. Políticas de revalidação de diplomas de pós-graduação em direito no Brasil: dificuldades e desafios para o sistema brasileiro. Revista Brasileira de Políticas Públicas, Brasília, DF, v. 2, n. 1, p. 143-161, jan.jun. 2012 doi: 10.5102/rbpp.v2i1.1814, p. 147. 
1994, o número de programas de mestrado salta para 21 e os cursos de doutorados dobram. Entre 1995 e 2000, o sistema alcança outro patamar: $66 \%$ de aumento de programas em cinco anos. Entre 2000 e 2005, o número de cursos sobe apenas cerca de $30 \%$, mas diferentes programas são criados, em várias regiões do país. Entre 2005 e 2010, há um novo impulso, com a criação de 11 novos programas de mestrado e 9 de doutorado. No mesmo período, nota-se que muitos cursos foram fechados, sobretudo cursos novos que não conseguiram manter os níveis prometidos de qualidade. $\mathrm{Na}$ avaliação trienal de 2009, 11 cursos foram rebaixados, sendo a área de Direito a que mais fechou cursos em todo o sistema nacional de pós-graduação.

A realidade se deixava mostrar pelo quadro comparativo da situação de $2010: 29$

Figura 1. Expansão da Pós-Graduação em Direito no Brasil

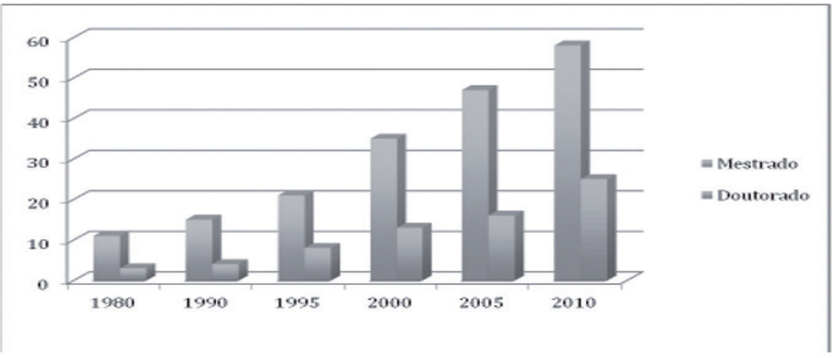

Inexiste notícia de acompanhamento de tais cursos oferecidos fora do Brasil. Ao contrário, o quadro que se tinha era aquele de distância entre o que era exigido no Brasil para a obtenção dos títulos de mestre ou de doutor daquele título eventualmente obtido nessa oferta "express". O caso mais destacado era na Argentina: ${ }^{30}$

A Universidad del Museo Social Argentino (UMSA) foi criada em 1965 e tem sua pós-graduacao em Direito reconhecida pelo Ministério da Educação da Argentina, por meio da Comisión Nacional de Evaluación y Acreditación Universitaria (CONEAU), que realizou uma avaliação na instituição em 2001, creditando o curso por três anos. No entanto, o curso foi expressamente "desacreditado" em dezembro de 2011, pela CONEAU, e ainda assim continuou funcionando, ampliando de forma massiva o número de doutorandos brasileiros inscritos.

\footnotetext{
$29 \quad$ Id. Ib, p. 148.
}

30 Id. Ib., p. 150. 
Havia inúmeros outros cursos ofertados nos níveis de mestrado e doutorado mesmo na Argentina, Chile, Paraguai, Portugal e Itália de perfil semelhante: não se tinha informações sobre integração docente e discente em grupos de pesquisa, redes de pesquisadores, exigência de publicação em periódicos classificados, forma de seleção.

Não há como se impedir que a titulação de mestre e doutor em Direito obtida no exterior venha a ser revalidada no Brasil. $\mathrm{O}$ desafio reside precisamente em reconhecer que, para tal revalidação, há correspondência com o que se exige no Brasil para a obtenção desses graus. Eis o mecanismo que serve de medida mundo afora, e não somente para cursos de pós-graduação. Se é correta a decisão da integração internacional, no âmbito regional e intercontinental, como se prevê nas diferentes políticas setoriais de blocos econômicos do qual o Mercosul é um deles, por outro lado não há como se esvaziar os esforços que cada nação tem realizado a fim de aperfeiçoar sua política de desenvolvimento científico.

Foi sob mencionado prisma que desde 1996 foi aprovada a Lei $n^{\circ} 9.394$, de 20 de dezembro daquele ano, e que estabelece as diretrizes e bases da educação nacional. Após explicitar, em seu art. 44, III, que a educação superior abrange os cursos “de pós-graduação, compreendendo programas de mestrado e doutorado, cursos de especialização, aperfeiçoamento e outros, abertos a candidatos diplomados em cursos de graduação e que atendam às exigências das instituições de ensino", estabelece ainda as normas para a revalidação dos diplomas expedidos fora do Brasil:

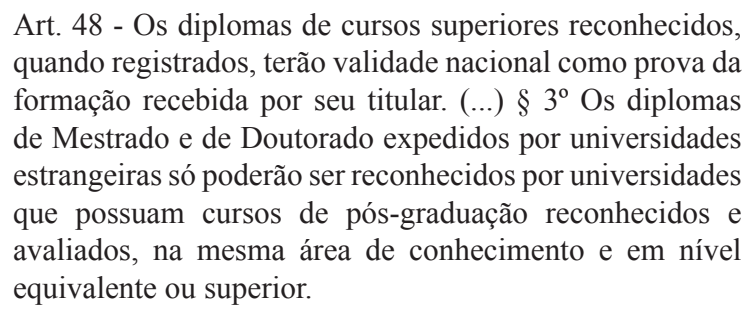

Portanto, em nada corresponde à realidade objetiva dos marcos legais a alegada "reserva de mercado" que a comunidade científica do Direito pretende, a fim de impedir a recepção no Brasil de diplomas obtidos por cursos oferecidos no exterior, mas que não atendam os critérios exigidos e aplicados às instituições de ensino superior brasileiras. O que não pode ser esquecido é o fato de que as buscas pela tentativa de amadurecimento e inserção internacional da pós-graduação em Direito no Brasil tem observado como parâmetro o que há de mais relevante nas outras áreas do conhecimento, sejam elas dentro ou fora do País. 
O desafio remanesce. Desde 2011 tramita na Câmara dos Deputados o PL $n^{0} 1.981$, cuja ementa é a seguinte: ${ }^{31}$

Estabelece os procedimentos e critérios de que trata o artigo primeiro do Acordo de admissão de títulos e graus universitários para o exercício de atividades acadêmicas nos estados partes do MERCOSUL promulgado pelo Decreto $\mathrm{n}^{\mathrm{o}} 5.518$, de 2005, relativos aos títulos de pósgraduação e unicamente para o exercício de atividades de docência e pesquisa nas instituições de ensino superior no Brasil e dá outras providências.

A redação do art. $2^{\circ}$ do Projeto de Lei ${ }^{\circ} 1.981 / 2001$ não deixa dúvidas quanto o sentido contrário ao $\S 3^{\circ}$ do art. 48 da Lei $n^{\circ} 9.394 / 1996$, acima transcrito: ${ }^{32}$

Art. $2^{\circ}$ - A admissão de títulos de pós-graduação expedidos por instituições ou estabelecimentos de ensino superior estrangeiros, situados em quaisquer dos Estados Partes do MERCOSUL, quando o fim visado for unicamente o exercício de atividades de docência e pesquisa nas instituições de ensino superior no Brasil, dar-se-á independente de reconhecimento ou revalidação ou qualquer outro procedimento que não o previsto nesta lei.

Conforme se pode concluir, a perspectiva da abertura de inserção regional e internacional que a pós-graduação da Área em Direito possui, e que assim tem permanecido por décadas, difere daquela de sendo comum. $\mathrm{O}$ que a pós-graduação brasileira em Direito pretende é a criteriosa inserção internacional de sua produção científica, com a preservação da elevada qualidade, seguida por parâmetros internacionais comumente respeitados.

31 Disponível em: https://www.camara.leg.br/busca-portal?contextoBusca=BuscaProposicoes\&pagina $=1 \&$ order $=$ relevancia\&abaEspecifica $=$ true\&filtros $=\% 5 \mathrm{~B} \% 7 \mathrm{~B} \% 22$ numero $\% 22 \% 3 \mathrm{~A} \% 221981 \% 22 \% 7 \mathrm{D}$, \%7B\%22ano\%22\%3A\%222011\%22\%7D\%5D\&tipos=PL. Acesso em: 10 nov. 2020. O Projeto de Lei recebeu parecer favorável da Relatoria da Representação Brasileiro no Parlamento do Mercosul, em maio de 2012. Em junho de 2013 produziu-se parecer desfavorável à sua aprovação pelo então Relator na Comissão de Educação da Câmara dos Deputados. Desde 26 de maio de 2012 que Conselho TécnicoCientífico da Educação Superior da CAPES enviou nota técnica contrária ao Projeto de Lei no 1.981/2011 de revalidação automática de diplomas de pós-graduação obtidos no exterior (https://www.conjur. com. br/2012-jul-04/capes-revalidacao-automatica-diplomas-obtidos-exterior. Acesso em: 13 nov. 2020). O Projeto de Lei foi arquivado, havendo sido requerido seu desarquivamento em 6 de fevereiro de 2019, na conformidade do Requerimento $\mathrm{n}^{\circ}$ 240/2019.

32 Disponível em: https://www.camara.leg.br/proposicoesWeb/prop_mostrarintegra;jsessionid=E2A31E6 997FB7C841E053A9DCB3C84D4. proposicoesWebExterno1? codteor=906523\&filename=PL+1981/2011; Acesso em: 10 nov. 2020. 
Breves conclusões

O sistema brasileiro de pós-graduação em Direito possui um saldo positivo em seus cinquenta anos. Por óbvio, não devem ser ignorados os aspectos negativos: para sua superação é necessário que sejam estes pontos sempre tematizados e discutidos de forma organizada.

Partiu-se de um modelo quase sem controle para um modelo totalmente informatizado, o que torna possível aos agentes públicos e a comunidade científica o acompanhamento constante de ajustes e necessidades, além do planejamento para o futuro. O que chama a atenção é a rapidez da implementação de elevado volume de modificações a confirmarem uma trajetória progressiva da organização geral da política científica brasileira de pós-graduação.

De acompanhamento a incidir somente sobre poucos critérios objetivos, como número de ingressos e egressos, foi elaborada outra estrutura capaz de produzir uma radiografia geral da atividade científica nacional: passou-se a avaliar desde instalações físicas e equipamento até a centralidade da produção científica docente e discente.

A pós-graduação brasileira em Direito, embora presente em quase todo o território nacional, mostra-se desigual, com áreas consideráveis de ausência de programa, como as regiões Centro-Oeste e Norte. Chama a atenção o desenvolvimento e instalação de programa de pós-graduação da região Nordeste, presente em todos os Estados dessa região. Ainda assim, a distribuição espacial mostra desigualdades, com a presença de um único programa no interior do Nordeste, centralizando nas suas capitais a pesquisa de nível de excelência da área de Direito.

A mudança mais significativa começou no final dos anos noventa, com discussões e elaboração de documentos de diretrizes científicas e o acompanhamento de regular periodicidade pela CAPES dos programas de pós-graduação. Neste instante, aparece a exigência sobre a produção científica, com a estrutura de sua veiculação e busca pela inclusão de outras ciências que sempre estiveram próximas ao Direito, mas que não realizavam diálogo interdisciplinar. A crescente formação de maior número de quadros para pesquisadores docentes, a recepção da produção estrangeira no Brasil tornou possível o acesso de cientistas brasileiros à produção e ao intercâmbio internacional, o que conduziu ao aperfeiçoamento da formação no sistema brasileiro de pós-graduação em Direito. O fomento à formação de redes de pesquisa entre regiões brasileiras e entre pesquisadores brasileiros e internacionais passou a ser concebido como elemento decisivo ao credenciamento da ciência do Direito brasileira no exterior. Este esforço produziu bons resultados, ainda que inferior ao esperado.

A expansão da graduação em Direito começou a pressionar a pósgraduação: a segunda não seguiu o modelo da primeira, na medida em que o crescimento dos cursos de pós-graduação passou a ser controlado por parâmetros mais rigorosos. Com 
um elevando contingente de graduandos que não conseguia ingresso na pós-graduação, presenciou-se o aparecimento de estratégia duvidosa de aparecimento de cursos fora do Brasil, cujas exigências não se comparavam àquelas da pós-graduação em Direito do País. Referida realidade deixou o campo da discussão acadêmica e hoje encontra espaço nas discussões do Poder Legislativo nacional, o que pode comprometer uma experiência razoavelmente exitosa de mais de vinte anos.

O sistema brasileiro da pós-graduação enfrentará sua mais recente avaliação quadrienal em 2021. Até aqui, os indicadores apontavam que, no geral, a escolha pela centralidade da produção científica de elevada qualidade, pela formação e consolidação de redes de pesquisa nacional e internacional foi acertada. O desafio será a manutenção dessa qualidade em ritmo mais acelerado da expansão. 